\title{
Status of chloroquine and hydroxychloroquine in COVID-19 infection
}

\author{
Savita Ramesh Shahani ${ }^{1 *}$, Lokesh R. Shahani²
}

\author{
${ }^{1}$ Department of Pharmacology, MGM Medical College, Navi Mumbai, Maharashtra, India \\ ${ }^{2}$ Department of Psychiatry and Behavioural Science, McGovern Medical School, Houston, Texas, USA
}

Received: 07 June 2020
Revised: 04 July 2020
Accepted: 08 July 2020

\section{*Correspondence:}

Dr. Savita Ramesh Shahani,

Email: drshahani@rediffmail.com

Copyright: (C) the author(s), publisher and licensee Medip Academy. This is an open-access article distributed under the terms of the Creative Commons Attribution Non-Commercial License, which permits unrestricted non-commercial use, distribution, and reproduction in any medium, provided the original work is properly cited.

\begin{abstract}
COVID-19 causing virus is a single stranded RNA virus which has spread across the globe causing human respiratory tract infection. The novel virus which started from Wuhan was named as Wuhan coronavirus or 2019 novel corona virus (2019-nCov) by the Chinese researchers. The international committee on taxonomy of viruses named the virus as SARS-CoV-2 and the disease as COVID-19. There is preliminary in vitro evidence of the ability of CQ and HCQ to inhibit SARS-CoV-2 activity. Various small group clinical studies conducted in china indicated efficacy of chloroquine and hydroxychloroquine in Covid-19 cases but results were inconclusive. Based on these studies national agencies in various countries issued guidelines mentioning that chloroquine and Hydroxychloroquine are only to be used in clinical trials or emergency use programs. However, USFDA does not recommend use of both these drugs for treatment of COVID-19 cases. Chloroquine and hydroxychloroquine are known to produce dose dependent toxicity including fatal arrhythmias therefore its possible benefit has to be assessed against its risk. Large number of international and national studies are ongoing to assess exact status of chloroquine and hydroxychloroquine for treatment and prophylaxis of COVID-19 infection. Based on these results ICMR recommend to use hydroxychloroquine for prophylaxis of COVID-19 in India and hydroxychloroquine has been is included in schedule H1 hence they can be sold by pharmaceutical chemists only strictly with a valid prescription and require record to be maintained but chloroquine is still under schedule $\mathrm{H}$ which require to be sold with prescription.
\end{abstract}

Keywords: Chloroquine hydroxychloroquine, COVID-19, SARS-CoV-2

\section{INTRODUCTION}

COVID-19 causing virus is a single stranded RNA virus which has spread across the globe causing human respiratory tract infection. This virus has crown-like spikes on their outer surface; thus, it was named as a coronavirus (coronam is the Latin term for crown). The novel virus which started from Wuhan was named as Wuhan coronavirus or 2019-novel corona virus (2019nCov) by the Chinese researchers. The international committee on taxonomy of viruses named the virus as SARS-CoV-2 and the disease as COVID-19. ${ }^{1}$ In January 2020, during the 2019-20 corona virus pandemic,
Chinese medical researchers stated that exploratory research into chloroquine (CQ) seemed to have fairly good inhibitory effects on the SARS-CoV-2 virus. $^{2}$

CQ was discovered in 1934, by Hans Andersag and co-workers' German scientists at the Bayer laboratories in a process to discover a substitute for quinine as antimalarial agent, and it was named as Resochin. ${ }^{3}$ In initial evaluation, the drug was discarded, as it was considered too toxic for human use. This was later considered a major mistake (the "resochin error", using the drug's German trade name). In 1943 large number of compounds were evaluated for its antimalarial activity in 
United State government sponsored clinical trials for antimalarial drug development, and CQ which is a 4-AQ derivative has shown a significant therapeutic value against malarial infection.

CQ has a good oral absorption with bioavailability of around $80 \%$. It has a very large apparent volume of distribution due to extensive sequestration into various tissues particularly liver, spleen, lungs, melanin containing tissue, therefore is widely distributed in body tissues. Its metabolism is partially hepatic, giving rise to its two main metabolites, desethylchloroquine and bisdese-ethyl chloroquine. Its excretion is $\geq 50 \%$ as unchanged drug in urine, and acidification of urine increases its elimination. It has a terminal half-life of 3060 days due to slow elimination from storage sites. ${ }^{4}$

CQ is used for treatment of malaria in adults in dose of $600 \mathrm{mg}$ CQ base as loading dose followed by $300 \mathrm{mg}$ at 8,24 and 48 hours which is equivalent to a total of 1500 $\mathrm{mg}$ base (equivalent to $2500 \mathrm{mg}$ of chloroquine phosphate) in 48 hours. It is used as prophylactic regimen in malaria in dose of $300 \mathrm{mg}$ CQ base weekly.

\section{ADVERSE REACTIONS OF CQ}

Taken in therapeutic dose it is a safe drug however it has a narrow margin of safety. Dose of CQ used for oral therapy may cause some of these following ADRs GIT upset like-nausea, vomiting, diarrhea, abdominal cramps, unpleasant metallic taste.

Dermatological disorder itching, skin color changes, hair loss, and skin rashes. CQ-induced itching is very common among black Africans $70 \%$, may be due to genetic characteristics. In 2014, Stevens-Johnson syndrome was added as an adverse drug reaction into the prescribing information leaflet of chloroquine in India.5 Ocular toxicity like blurring of vision, diplopia, CNS toxicity like headache confusion convulsions. Hematological disorder pancytopenia, aplastic anemia, reversible agranulocytosis, low blood platelets, neutropenia. Cardiovascular toxicity widening of QRS complex and $\mathrm{T}$ wave abnormalities.

Prolong therapy used for prophylaxis of malaria may produce toxic myopathy, cardiopathy, peripheral neuropathy and retinopathy. There is not enough evidence to determine whether CQ is safe to be given to people aged 65 and older.

Because of toxicities observed with CQ, another 4AQ derivative hydroxychloroquine (HCQ) was synthesize in 1946 in an attempt to discover less toxic substitute for malaria. HCQ is a hydroxylated derivative of CQ has similar antimalarial activity and was demonstrated to be much less $(\sim 40 \%)$ toxic than CQ in animals. Study conducted by Finbloom et al shows that HCQ has much lesser incidence of retinopathy compared to CQ. Thus, HCQ can be used safely with minimal risk of toxicity. ${ }^{6}$

\section{MECHANISM OF ACTION OF CQ AS ANTI- MALARIAL AGENT}

CQ is a lysosomotropic agent, therefore it accumulates preferentially in the lysosomes of cells in the body. The $\mathrm{pK}_{\mathrm{a}}$ for CQ is 8.5 , which means that at $8.5 \mathrm{pH}$ it remains as $50 \%$ deprotonated and $50 \%$ as protonated form, while at physiological $\mathrm{pH}(7.4)$ it is about $90 \%$ protonated (as per the Henderson-Hasselbalch equation) further at lysosomal $\mathrm{pH}$ of $4.6 \mathrm{CQ}$ is protonated up to $99 \% .^{7}$ As the protonated form is not membrane permeable and quantitative 'trapping' of the $\mathrm{CQ}$ in lysosomes results. The lysosomotropic character of CQ account for much of its antimalarial activity, the drug concentrates in the acidic food vacuole of the parasite inhibits haempolymerase of the parasite, leading to the accumulation of soluble haem which is toxic for the parasite. ${ }^{8}$ Same lysosomal toxicity is probably responsible for its action against other infections.

\section{ANTI-VIRAL ACTION OF CQ/HCQ}

Apart from malaria, some of the studies have reported antiviral effects of CQ. ${ }^{9} \mathrm{CQ}$ had been also been proposed as a treatment for COVID-19, as in vitro tests shows inhibition of the severe acute respiratory syndrome (SARS-CoV) virus by CQ. Keyaerts et al reported that CQ acts as an effective inhibitor of the replication of the SARS-CoV in vitro. ${ }^{10}$ There is preliminary in vitro evidence of the ability of CQ and HCQ to inhibit SARSCoV-2 activity. Liu et al observed a similar 50\% cytotoxic concentration for CQ and HCQ, however, the $50 \%$ maximal effective concentration was lower for CQ than HCQ, irrespective of viral load in host cells suggesting CQ may be more efficacious in similar plasma concentration invitro. ${ }^{11}$

By contrast, Yao et al observed that HCQ was more potent against SARS-CoV-2 than CQ in vitro (EC50 of $0.72 \mu \mathrm{M}$ and $5.47 \mu \mathrm{M})$ respectively. ${ }^{12}$ Wang et al reported in vitro antiviral activity of CQ, with an EC50 of $1.13 \mu \mathrm{M}$ and CC50 $>100 \mu \mathrm{M}$ with high selectivity for SARS-CoV-2 rather than host cells. ${ }^{13}$ This concentration of $\mathrm{CQ}$ is much lesser than the plasma concentration achieved in human in treatment of malaria with usual dose of $25 \mathrm{mg} / \mathrm{kg}$ over 3 days, however dose of 3.6 $\mathrm{mg} / \mathrm{kg} /$ week which is used for prophylaxis of malaria may produce plasma concentration of $1-3 \mu \mathrm{mol} / 1$ which is the concentration range equivalent to require for IC50 for SARS-CoV2 inhibition. HCQ has shown greater efficacy in in vitro studies. Future studies might tell us most effective schedule of administration and potential adverse events.

\section{MECHANISM OF ACTION OF CQ/HCQ IN COVID-19}

The main target cells of CQ for the SARS-CoV-2 are in enterocytes and pneumocytes in which it enters in high concentration after administration. CQ increases 
endosomal and lysosomal pH and inhibits entry of SARSCoV-2 into cells as well as inhibit viral replication. ${ }^{14}$ The author speculated that CQ and HCQ in addition could have impact on disease severity in COVID-19 through modulating the excess cytokine release by mediating an anti-inflammatory response, which might reduce damage due to the exaggerated inflammatory response. CQ also seems to act as a zinc ionophore that allows extracellular zinc to enter the cell and inhibit viral RNAdependent RNA polymerase. ${ }^{15}$

\section{EFFECT OF CQ/HCQ AGAINST COVID-19 PATIENTS}

A great deal of effort has been made to find effective drugs against the COVID-19 in China, as this infection started from this country. Most guidelines cite interim results of two studies. A brief study mentioning results from more than 100 patients have demonstrated that $C Q$ is superior to the conventional treatment in inhibiting the exacerbation of pneumonia, improving lung imaging findings, promoting a virus negative conversion, and shortening the disease course. ${ }^{16}$

In a pilot study aiming to evaluate the efficacy and safety of CQ in inpatients with COVID-19, 10 patients (3 with severe disease and 7 with moderate disease) received $\mathrm{CQ}$ (300 mg base) orally twice a day for 10 days, and 12 patients (5 with severe disease and 7 with moderate disease) received lopinavir and ritonavir $400 \mathrm{mg}$ and 100 $\mathrm{mg}$ orally twice a day for 10 days. CQ was slightly superior to lopinavir and ritonavir in terms of virus clearance, since the CQ group tested negative for SARSCoV-2 at slightly better rate than the control group on 7 , 10, and 14 days post-treatment. However, CQ was superior to lopinavir and ritonavir in improving the radiological appearance of the lungs and decreasing the duration of hospitalization. All ADRs observed with CQ were tolerable and CQ was not discontinued in any of the patients during the treatment period. ${ }^{17}$ Due to its promising preliminary information, CQ has been included in guidelines for the diagnosis and treatment of COVID-19 (sixth edition) published by the National Health Commission of the People's Republic of China. ${ }^{18}$

CQ has also been approved by, South Korean and Italian health authorities for the experimental treatment of COVID-19. ${ }^{19,20}$ These agencies notified people with heart disease and diabetes as contraindications. On March $28^{\text {th }}$ 2020 the USFDA authorized the use of HCQ and CQ under an emergency use authorization which was revoked back on $15^{\text {th }}$ June 2020. ${ }^{21}$ On 1 April 2020, the European medicines agency issued guidelines that CQ and HCQ are only to be used in clinical trials or emergency use programs. ${ }^{22}$ The Indian Council of Medical Research (ICMR), has recommended chemoprophylaxis with HCQ for asymptomatic healthcare workers treating patients with suspected or confirmed COVID-19, and for asymptomatic household contacts of confirmed cases. ${ }^{23}$
This was revised on $23^{\text {rd }}$ May 2020 to expand its indication.

\section{SOME OF THE CLINICAL TRIALS REGARDING USE OF CQ/HCQ IN COVID-19}

Exact status of CQ/HCQ as pharmacotherapy of COVID19 still required to be assessed. Result of some of the published work is discussed here. A parallel, doubleblinded, randomized, phase $2 \mathrm{~b}$ clinical trial to assess the safety and efficacy of 2 different doses of CQ as adjunctive therapy of hospitalized patients with severe acute respiratory syndrome (SARS) due to COVID-19 was planned in Brazil. Participants were randomized to either high or low dose of CQ. Patients in high dose CQ group received $600 \mathrm{mg} C Q$ base twice daily dose over 10 days (a total of $12 \mathrm{gm}$ total dose over 10 days), while patients in low dose CQ received $450 \mathrm{mg}$ of CQ base twice daily on day 1 and once daily for next 4 days (a total of $2.7 \mathrm{gm}$ in five days). The study was halted temporarily after enrolling 81 patients, as by $6^{\text {th }}$ day 11 participants died. On decoding it was observed that the group of patients taking a high dose of the CQ, some of them developed dangerous heart rhythm problems. It was seen more often in older patients with concomitant use of azithromycin (AZ) which also prolong QTc interval. ${ }^{24}$ As a consequence study was halted in high dose CQ group and shifted them to low dose CQ.

On April 24 the USFDA cautioned against using the drug outside a hospital setting or clinical trial after reviewing adverse events including ventricular tachycardia, ventricular fibrillation, and death. ${ }^{25}$ During this time of crisis it is important to prioritize clinical trials evaluating important questions regarding $\mathrm{CQ}$, such as its dosing in prophylaxis, and treatment in COVID-19. It is also important to convey clear messages that reflect the proper interpretations of available data which must be disseminated.

In COVID-19 clinical trial, one small non-randomized study from France demonstrated beneficial effect of HCQ. ${ }^{26}$ This study with 36 participants had a variable patient profile like, 6 asymptomatic, 22 with upper respiratory tract infection symptoms and eight with lower respiratory tract infection symptoms. While another six patients who were not the part of study were considered as control, who received standard care. Out of 36 participants 26 patients received HCQ along with standard care while remaining 10 participants received standard care. Twenty cases receiving HCQ showed a significant reduction of the viral load on Day-6-post CQ treatment, compared to controls, and much lower average carrying duration compared to untreated patients in the literature. AZ added to $\mathrm{HCQ}$ in 6 patients was significantly more efficient for virus elimination. Six participants receiving HCQ were lost to follow up and author concluded that HCQ treatment is associated with significant $(\mathrm{p}<0.001)$ viral load reduction/disappearance in Covid-19 patients and its effect is potentiated by AZ. 
This study has some limitations including a small sample size which is not sufficient to achieve sufficient power in statistics, limited long-term outcome follow-up, and dropout of six patients from the study which were not considered during statistical analysis. In addition, this study lacked matching control group, however in the current context, author felt that these results should be shared with the scientific community.

Yet, another very small, randomized study from China in patients with mild to moderate COVID-19 found no difference in recovery rates in patients treated with HCQ (400 mg per day for 5 days plus conventional treatments), compared to control group receiving conventional medical care only. 27 author concludes that larger sample size study may be needed to investigate the effects of HCQ in the treatment of COVID-19.

Similar findings were observed by Boulware et al who conducted a randomized, double-blind, placebocontrolled trial in United States and Canada testing HCQ as post-exposure prophylaxis in asymptomatic participants who had known exposure to a person with laboratory-confirmed Covid-19, like a household contact, health care worker, person with other occupational exposures. All participants received either HCQ in dose of $800 \mathrm{mg}$ once, then after 6 to 8 hours $600 \mathrm{mg}$ as a loading dose, followed by $600 \mathrm{mg}$ daily for 4 more days for a total course of 5 days (total $3800 \mathrm{mg}$ ) or matching placebo. This trial did not demonstrate any significant benefit of HCQ as post-exposure prophylaxis for COVID-19 up to 14 days of follow up. This study had not explored its role in pre-exposure prophylaxis. ${ }^{28}$ There was no serious intervention-related adverse reactions including cardiac arrhythmias. Limitation of this study was that approximately $60 \%$ of the participants were not using any personal protective equipment during their COVID-19 exposure. Time of exposure to COVID-19 patient and intake of interventional agent was not uniform. All participants under study did not have confirmed lab test for virus, majority of them were assessed based on COVID-19 related symptoms thus asymptomatic infected people were not added in interventional group. Outcome of study was assessed based on information given by participants through internet.

In addition to efficacy, 4AQs can cause ventricular arrhythmias, QT prolongation, and other cardiac toxicity, which may pose risk particularly to critically ill persons. Therefore, well-performed randomized trials that can clarify exact status of CQ and HCQ in COVID-19. Wide use of HCQ may expose some patients to rare but potentially fatal harms, including serious cutaneous adverse reactions, fulminant hepatic failure, and ventricular arrhythmias (especially when prescribed with AZ). ${ }^{29-31}$ Moreover, the safety of these immunomodulation by HCQ in people at risk of a severe viral illness has never been evaluated.
As of now, supportive care is the therapy for majority of COVID-19 cases. It is very important that healthcare professionals use CQ and HCQ only for their authorized uses or as part of clinical trials or national emergency use programs for the treatment of COVID-19. Both CQ and HCQ can have serious side effects, especially at high doses or when combined with other medicines. Large clinical trials are under way to generate the data needed to establish the efficacy and safety of CQ and HCQ in the treatment of COVID-19.

Some of the ongoing clinical trials related to $\mathrm{CQ}$ in covid-19 are mentioned below. A large, randomized multicentric phase III clinical trial, discovery (clinical trials.gov identifier: NCT04315948), sponsored by Institute National de la Sante Et de la Recherche Medicale, France involves all COVID-19 confirmed patients with moderate disease. All participants will be given usual standard of care. While intervention group will receive apart from standard care any one of following treatment remdesivir, lopinavir and ritonavir, lopinavir and ritonavir plus interferon B-1a 4hydroxychloroquine. The primary endpoint of the study was clinical status of patients after 2 weeks to assess efficacy and safety of various regimens. ${ }^{32}$

This clinical trial (clinical trials.gov identifier: NCT04328493) is sponsored by Oxford University Clinical Research Unit, Vietnam. This is a phase II open label, randomized, controlled trial that will be conducted in in-patients with aim to evaluate potential therapeutics of CQ in the treatment of hospitalized COVID-19. The study will start as observational pilot study and once initial results are approved by data safety board regular study will be conducted in 250 participants. Patients will be randomized to the intervention arm who will receive CQ (loading dose of $1200 \mathrm{mg}$ CQ base over the first 24 hours followed by $300 \mathrm{mg}$ once daily for 9 days) along with standard of care therapy, while control arm will receive only standard care therapy. All participants will be assessed up to 56 days post randomization for time to viral clearance and safety of drug. ${ }^{33}$

Clinical trials.gov identifier: NCT04370262 sponsored by Northwell Health USA is a multi-site, randomized, double-blind, multi-arm historical control, comparative trial to assess safety and efficacy of HCQ alone, and the combination of HCQ and famotidine for the treatment of moderate to severe COVID-19. Since HCQ became the standard care treatment for COVID-19 shortly after this time period, researcher felt it would be unethical to randomize patients in this trial to a control arm without any active investigational medications. This study will review data previously collected on patients not treated with HCQ to compare to the active treatment arms. About 1200 COVID-19 participants will receive a loading dose of HCQ $400 \mathrm{mg}$ twice daily on day 1, followed by 200 $\mathrm{mg}$ twice daily for 4 days, or a loading dose of $800 \mathrm{mg} 4$ times daily on day 1 , followed by $400 \mathrm{mg} 4$ times daily for 4 days, as per clinical protocol for COVID-19. In 
addition, participants will receive intravenous famotidine, $120 \mathrm{mg}$, (the total daily dose proposed is 360 $\mathrm{mg} /$ day)/placebo as per randomization for a maximum of 14 days. The aim of study is to compare mortality status, viral clearance and severity of disease between 2 interventional groups up to follow up period of 30 days. The interventional group will be compared with historical control. ${ }^{34}$ This study was designed based on the retrospective cohort study conducted by Freedberg et al who observed that use of famotidine is associated with reduced risk of intubation or death in hospitalized COVID-19 patients. $^{35}$

Clinical trials.gov identifier: NCT04333628 sponsored by HaEmek Medical Center, Israel to assess effect of CQ for mild symptomatic and asymptomatic COVID-19. The purpose of this study is to test whether a low dose of CQ will reduce the duration of the viral shedding and prevent the disease from worsening. This is a phase 2 and phase 3 trial in 210 participants. The trial will be conducted in two stages. In first phase patients with mild-grade symptomatology disease will receive either low dose of CQ (125 mg daily) or regular dose of CQ (500 mg twice daily) for 7 days, while the control group will receive only standard care. Depending on the results of the first phase, Investigators will consider the second stage, in asymptomatic carriers to study whether CQ therapy in asymptomatic patients decrease duration of viral shedding and prevent the onset of symptomatic disease. ${ }^{36}$

Clinical trials.gov identifier: NCT04303507 sponsored by University of Oxford entitled will be conducted in 40,000 participants from various countries. The study is a double-blind, randomized, placebo-controlled trial involving around 40,000 healthcare workers in a healthcare facility delivering direct care to patients with proven or suspected COVID-19. The participant will be randomized in Asia to receive either CQ base in loading dose of $10 \mathrm{mg}$ base $/ \mathrm{kg}$ (4×155 mg) followed by $155 \mathrm{mg}$ daily or placebo, or in European and African sites, HCQ $200 \mathrm{mg}$ daily or placebo for 90 days. If the participant is diagnosed with COVID-19, they will continue to take the study medication unless advised to stop by their healthcare professional. The study is aimed to assess difference in number of symptomatic COVID-19 cases between the CQ/HCQ and placebo groups. ${ }^{37}$ There are 3 registries on CTRI site for clinical trials on ' $\mathrm{CQ}$ and COVID-19 to be conducted in India.

CTRI number CTRI/2020/05/025067. It is a multicentric randomized, parallel group, controlled trial of HCQ prophylaxis for healthcare workers exposed to COVID19, which is sponsored by George Institute for Global Health India. Study is aimed to compare whether $800 \mathrm{mg}$ of HCQ on the day of enrollment followed by $400 \mathrm{mg}$ weekly for a total of 12 weeks along with standard care personal protection, has any protective effect in terms of proportion of laboratory confirmed symptomatic COVID19 cases compared to standard care personal protection. ${ }^{38}$
CTRI number CTRI/2020/04/024904. It is a randomized parallel group, controlled clinical trial to compare efficacy of HCQ alone and in combination with AZ in treatment of COVID-19 which is sponsored by Director General Armed Forces Medical Services New Delhi. Aim of study is to compare if there is any difference in outcome of patients treated with high dose HCQ $(600 \mathrm{mg}$ BD D1, HCQ 300 mg BD D2-D50 vs low dose HCQ 400 $\mathrm{mg} \mathrm{BD}$ on $\mathrm{D} 1$ and $400 \mathrm{mg}$ OD on D2-5I) vs low dose HCQ and AZ in two different doses taken together (HCQ $400 \mathrm{mg}$ BD AZT $500 \mathrm{mg}$ OD vs D1 HCQ $400 \mathrm{mg}$ OD AZT $250 \mathrm{mg}$ OD D2-D5). ${ }^{39}$

CTRI number CTRI/2020/04/024479. It is an open labeled randomized parallel group, controlled trial to study the effect of CQ in addition to standard therapy in Covid-19 patients which is sponsored by Command Hospital Bangalore. Study is aimed to compare effect of chloroquine phosphate $(500 \mathrm{mg}$ twice daily for 10 days compared to standard treatment to observe if there is any difference in number of days of hospitalization /discharge between the 2 groups. ${ }^{40}$

CTRI number CTRI/2020/03/024402. This is a randomized, parallel group in open labeled, clinical trial to assess efficacy of HCQ treatment in conventional dose as per ICMR regimen (400 $\mathrm{mg}$ twice daily for one day followed by $400 \mathrm{mg}$ weekly for 7 weeks) vs low dose (300 mg daily x7 days followed by $300 \mathrm{mg}$ weekly x 7 weeks) for prevention of new infection and adverse outcomes following COVID-19. The study is sponsored by Aster Malabar Institute of Medical Sciences. Kozhikode Kerala. ${ }^{41}$

\section{"SOLIDARITY" CLINICAL TRIAL FOR COVID- 19 TREATMENTS ${ }^{42}$}

"Solidarity" is an international clinical trial to help find an effective treatment for COVID-19, launched by the WHO and partners. This study was planned to compare four treatment options against standard of care, to assess their relative effectiveness against COVID-19 to assess whether any of the drugs reduce disease progression or improve survival. COVID-19 patient is randomized to receive either only standard care or one of the following four regimen with standard care remdesivir, HCQ, lopinavir and ritonavir, lopinavir and ritonavir plus interferon beta- $1 \mathrm{a}$. The outcome of various regimens will be compared in terms of duration of hospital stay, supportive care needed, outcome of treatment.

The ICMR, has recommended chemoprophylaxis with HCQ (400 mg twice on day 1, then $400 \mathrm{mg}$ once a week for 7 weeks) for asymptomatic healthcare workers treating patients with suspected or confirmed COVID-19, and for asymptomatic household contacts of confirmed cases (400 mg twice on day 1 , then $400 \mathrm{mg}$ once a week for 3 weeks). ${ }^{23}$ 
Chinese guidelines advise consideration of $\mathrm{CQ}$ in all hospitalized patients, although has advised caution regarding dosing and special patient groups. ${ }^{43}$ The WHO, the US centers for disease control and prevention, and public health England are yet to recommend CQ or HCQ for treatment. ${ }^{44}$ To reduce the risk of adverse effects of CQ, the Republic of China seventh in edition of the guidance, issued on 3 March 2020, recommended to reduced dosage and shortened duration of treatment. Recommended dose of CQ for adult patients with a body weight $>50 \mathrm{~kg}$ is $500 \mathrm{mg}$ twice a day for 7 days and for adult with body weight $<50 \mathrm{~kg}$ is $500 \mathrm{mg}$ twice a day for the first 2 days and $500 \mathrm{mg}$ once a day for the following 3-7 days. $^{45}$

A multi-national registry analysis was done to assess efficacy of use of HCQ or CQ with or without a macrolide for treatment of COVID-19. The registry comprised data from 671 hospitals in six continents. Study included patients hospitalized with a SARS-CoV-2 infection. Patients who received one of the treatments of interest within 48 hours of diagnosis were included in one of four treatment groups (CQ alone, CQ with a macrolide, HCQ alone, or HCQ with a macrolide), and patients who received none of these treatments formed the control group to assess in-hospital mortality and the occurrence of de-novo ventricular arrhythmias. 96032 patients hospitalized with COVID-19 during the study period were included in the study, out of them 14888 patients were in the treatment groups (1868 received CQ, 3783 received CQ with a macrolide, 3016 received $\mathrm{HCQ}$, and 6221 received HCQ with a macrolide) and 81144 patients were in the control group. After controlling for multiple confounding factors when various groups were compared to control, it was observed that each group of interventional drugs were independently associated with an increased risk of in-hospital mortality and de-novo ventricular arrhythmia during hospitalization. Therefore, author interpreted that results do not support benefit of HCQ or CQ, when used alone or with a macrolide, in hospitalized COVID-19 patients. ${ }^{46}$

Based on the findings of the above online publication WHO suspended temporarily HCQ arm in the solidarity trial, till safety data is reviewed by the data safety monitoring board. WHO chief scientist clarified that the WHO-backed solidarity trial is planned to consider only at the effects of HCQ and not CQ. Based on the information available if HCQ is to be used, a clear informed choice needs to be offered to every contact, explaining the scarcity of evidence for its efficacy and its potential risks. Additionally, all outcome events should be recorded for the risk-benefit assessment. ${ }^{47}$ On $3^{\text {rd }}$ June 2020, WHO's director-general, mentioned that the board reviewed the available mortality data and found "no reasons to modify the trial." and allowed the investigators to resume their clinical trial. ${ }^{48}$

ICMR updated its advisory on $23^{\text {rd }}$ May 2020, to extend the usage of HCQ as a preventive treatment against the
SARS-CoV-2 infection. Based on the findings of the studies, the government has decided to administer HCQ as a prophylaxis to asymptomatic healthcare workers working in non-COVID hospitals, non-COVID blocks of hospitals earmarked for COVID-19 treatment, asymptomatic frontline workers, such as surveillance workers deployed in containment zones, paramilitary and police personnel involved in COVID-related activities. While the dosage will remain the same as before for eight weeks, the ICMR advisory suggests that it can be used beyond that period as well, but with close monitoring of clinical and ECG parameters, to ensure that the therapy is given under supervision. ${ }^{49}$

This advisory is issued based on a retrospective casecontrol analysis at ICMR showing that there is a significant dose-response relationship between the number of prophylactic doses taken and frequency of occurrence of SARSCoV-2 infection in symptomatic healthcare workers. However, in final results of the studies (HCQ prophylaxis among 1323 healthcare workers), ICMR observed mild adverse effects such as nausea, abdominal pain, vomiting, hypoglycaemia and cardio-vascular effects. The advisory states that the drug should be discontinued if it causes the rare cardiac side effects such as cardiomyopathy, heart-rate disorders and visual disturbance including blurring of vision, which is usually self-limiting and improves on discontinuation of the drug. ICMR has clarified that "for the above cited reasons the drug has to be given under strict medical supervision with an informed consent". The drug is not recommended for prophylaxis in children under 15 years of age and in pregnancy and lactation, the advisory said. ICMR has not issued any guidelines for use of CQ in COVID-19 cases. Another investigation from 3 central government hospitals in New Delhi indicates that amongst healthcare workers involved in COVID-19 care, those on HCQ prophylaxis were less likely to develop SARS-CoV-2 infection, compared to those who were not on it. In an observational prospective study of 334 healthcare workers at AIIMS New Delhi, it was observed that 248 participants who took HCQ prophylaxis had lower incidence of SARS-CoV-2 infection than those not taking it.

As seen with different studies investigators have used different doses. Again, doses used for prophylaxis of $\mathrm{CQ} / \mathrm{HCQ}$ is much lesser than if used for therapeutics. As both HCQ and CQ causes dose and duration dependent toxicity, therefore given for prophylaxis for appropriate duration may be less likely to cause toxicity. Therefore, ICMR has issued a strict advisory mentioning that they must not be used without a prescription and without supervision by a physician and prescriptions should not be given outside their authorized uses. Therefore, the gazette of INDIA on 26th March, 2020 notified that HCQ is included in schedule H1 hence they can be sold by pharmaceutical chemists strictly with a valid prescription and separate register recording identity of the patient, contact details of the prescribing doctor and the name and 
dispensed quantity of the drug should be maintained. This record required to be retained for at least three years so a clear overview regarding consumption of HCQ can be obtained. This notification also does not put any restriction on use of CQ which is still under schedule $\mathrm{H}$ which requires to be sold with prescription but need not maintain its record. ${ }^{50}$

\section{CONCLUSION}

It is also important to convey clear messages that reflect the proper interpretations of available data regarding management of COVID-19, which must be disseminated. Physicians should be educated about the correct assessment of available data regarding HCQ and CQ in treating COVID-19, so that they can avoid misuse of HCQ and CQ especially for the prophylaxis of SARSCoV-2 infection. Well planned, clinical trials which are ongoing may through information regarding potential therapies, including the risk for serious adverse events, as current data to support the use of HCQ and CQ for COVID-19 are limited and inconclusive. Again, most of the recent studies and regulatory guidelines are regarding use of HCQ. Therefore, physicians should be educated about advantage of one drug over other to decide selection of CQ if at all this is prescribed by them.

Funding: No funding sources

Conflict of interest: None declared

Ethical approval: Not required

\section{REFERENCES}

1. Lai C, Shih T, Ko W, Tang H, Hsueh P. Severe acute respiratory syndrome coronavirus 2 (SARS-CoV-2) and corona virus disease-2019 (COVID19): the epidemic and the challenges. Int $\mathbf{J}$ Antimicrob Agents. 2020;55(3):105924.

2. Wang M, Cao R, Zhang L, Yang X, Liu J, Xu M, et al. Remdesivir and chloroquine effectively inhibit the recently emerged novel coronavirus (2019-nCoV) in vitro. Cell Res. 2020;30(3):269-71.

3. Krafts K, Hempelmann E, Stania SA. From methylene blue to chloroquine: a brief review of the development of an antimalarial therapy. Parasitology Res. 2012;111(1):1-6.

4. Krishna S, White NJ. Pharmacokinetics of quinine, chloroquine and amodioquine clinical applications. Clin Pharmacokinet. 1996;30:263-99.

5. Central Drugs Standard Control Organization. Directorate General of Health Services. Ministry of Health and Family Welfare. Government of India. Adverse drug reaction related notifications. Available at: https://cdsco.gov.in/opencms/opencms/en/ Notifications/Adverse Drug Reaction Related Notifications. Accessed on 3 March 2020.

6. Finbloom DS, Silver K, Newsome DA, Gunkel R. Comparison of Hydroxychloroquine and Chloroquine Use and the Development of Retinal Toxicity. J Rheumatol. 1985;12(4):692-4.
7. Bhagwan NV, Chung EH. Water, Acids, Bases, and Buffers. In Essentials of Medical Biochemistry with Clinical cases by (Second Edition). 2015, Pages1120. Elsevier Acedemic Press.

8. Hempelmann E. Hemozoin biocrystallization in Plasmodium falciparum and the antimalarial activity of crystallization inhibitors. Parasitology Res. 2007;100(4):671-6.

9. Savarino A, Boelaert JR, Cassone A, Majori G, Cauda R. Effects of chloroquine on viral infections: an old drug against today's diseases. Lancet Infectious Diseases. 2003;3(11):722-7.

10. Keyaerts E, Vijgen L, Maes P, Neyts J, Ranst VM. In vitro inhibition of severe acute respiratory syndrome coronavirus by chloroquine. Biochem Biophys Res Commun. 2004;323(1):264-8.

11. Liu J, Cao R, Xu M, Wan X, Zhang $H$. Hydroxychloroquine, a less toxic derivative of chloroquine, is effective in inhibiting SARS-CoV-2 infection in vitro. Cell Discov. 2020;6(1):1-4.

12. Yao X, Ye F, Zhang M, Cui C, Huang B. Vitro Antiviral Activity and Projection of Optimized Dosing Design of Hydroxychloroquine for the Treatment of Severe Acute Respiratory Syndrome Coronavirus 2 (SARS-CoV-2). Clin Infect Dis. 2020;9:237.

13. Wang M, Cao R, Zhang L, Yang X, Liu J, Xu M, et al. Remdesivir and chloroquine effectively inhibit the recently emerged novel coronavirus $(2019-\mathrm{nCoV})$ in vitro. Cell Res. 2020;30(3):269-71.

14. Bari AMA. Targeting endosomal acidification by chloroquine analogs as a promising strategy for the treatment of emerging viral diseases. Pharmacol Res Perspect. 2017;5(1):e00293.

15. Xue J, Moyer A, Peng B, Wu J, Hannafon BN. Chloroquine is a zinc ionophore. PloS One. 2014;9(10):e109180.

16. Gao J, Tian Z, Yang X. Breakthrough: chloroquine phosphate has shown apparent efficacy in treatment of COVID-19 associated pneumonia in clinical studies. Biosci Trends. 2020;14(1):72-3.

17. Huang M, Tang T, Pang P. Treating COVID-19 with Chloroquine. J Mol Cell Biol. 2020;12(4):322-5.

18. National Health Commission. Interpretation of the Sixth Edition of the Guidance for COVID-19: Prevention, Control, Diagnosis, and Management. Available at: http://www.nhc. gov.cn/xcs/fkdt/202 002/54e1ad5c2aac45c19eb541799bf6 37e9.shtml. (in Chinese).

19. Physicians work out treatment guidelines for coronavirus. m.koreabiomed.com (in Korean). 13 February 2020. Accessed on 17 March 2020.

20. Azioni intraprese per favorire la ricerca e l'accesso ai nuovi farmaci per il trattamento del COVID-19. aifa.gov.it (in Italian). Retrieved 18 March 2020.

21. RADM Denise M. Hinto. Food and Drug Administration. Coronavirus (COVID-19) Update: FDA Revokes Emergency Use Authorization for Chloroquine and Hydroxychloroquine. Available at: https://www.fda.gov/news-events/press-announc- 
ements/coronavirus-covid-19-update-fda-revokesemergency-use-authorization-chloroquine-and Hydroxychloroquine. Accessed on 15 June 2020.

22. COVID-19: chloroquine and hydroxychloroquine only to be used in clinical trials or emergency use programmes. European Medicines Agency. Available at: https://www.ema.europa. eu/en/documents/pressrelease/covid-19-chloroquinehydroxychloroquineonly-be-used-clinical-trialsemergency-useprogrammes_en.pdf. Accessed on 15 June 2020.

23. National Taskforce for COVID-19. Advisory on the use of hydroxy-chloroquine as prophylaxis for SARS-CoV-2 infection; 2020. Available at: https://www.mohfw.gov.in/pdf/AdvisoryontheuseofH ydrox ychloroquinasprophylaxisforSARSCoV2infecti on.pdf. Accessed on 15 June 2020.

24. Borba M, Val F, Sampaio V, Alexandre M, Melo G. Effect of High vs Low Doses of Chloroquine Diphosphate as Adjunctive Therapy for Patients Hospitalized with Severe Acute Respiratory Syndrome Coronavirus 2 (SARS-CoV-2) Infection A Randomized Clinical Trial. JAMA Netw Open. 2020;3(4):208857.

25. Research, Center for Drug Evaluation and (24 April 2020). FDA cautions against use of hydroxychloroquine or chloroquine for COVID-19 outside of the hospital setting or a clinical trial due to risk of heart rhythm problems FDA. Available at: https://www.fda.gov/drugs/drug-safety-and-availability/fda-cautions-against-use-hydroxychloroquineor-chloroquine-covid-19-outside-hospital-setting. Accessed on 15 June 2020.

26. Gautret P, Lagier J, Parola P, Hoang V, Meddeb L. Hydroxychloroquine and Azithromycin as a Treatment of COVID-19: Results of an Open-Label Non-Randomized Clinical Trial. Int J Anti-microb Agents. 2020:105949.

27. Chen J, Liu D, Liu L. A pilot study of hydroxychloroquine in treatment of patients with common coronavirus disease-19 (COVID19). Zhejiang Da Xue Xue Bao Yi Xue Ban. 2020;49(2):215-9.

28. Boulware R, Pullen F, Bangdiwala S, Pastick A, Lofgren M. A Randomized Trial of Hydroxychloroquine as Postexposure Prophylaxis for COVID-19. 3 June 2020, at NEJM.org.

29. Murphy M, Carmichael AJ. Fatal toxic epidermal necrolysis associated with hydroxychloroquine. Clin Exp Dermatol. 2001;26:457-8.

30. Makin A, Wendon J, Fitt S, Portmann B, Williams R. Fulminant hepatic failure secondary to hydroxychloroquine. Gut. 1994;35:569-70.

31. Malviya A. Ventricular arrhythmia risk due to chloroquine/hydroxychloroquine treatment for COVID-19: Should it be given. Indian Heart J. 2020;72(2):131-2.

32. Trial of Treatments for COVID-19 in Hospitalized Adults (discovery). Clinical trials.gov identifier: NCT04315948. Available at https://clinicaltrials.gov/ct2/show/NCT04315948.
33. The Vietnam Chloroquine Treatment on COVID-19 (VICO). Clinical trials.gov identifier: NCT04328493. Available https://clinicaltrials.gov/ct2/show/NCT04328493.

34. Multi-site Adaptive Trials Using Hydroxychloroquine for COVID-19 (match). Clinical trials.gov identifier: NCT04370262. Available at https://clinicaltrials.gov/ct2/show/NCT04370262.

35. Freedberg D, Joseph C, Wang T, Tracey K, Callahan M. Famotidine Use is Associated with Improved Clinical Outcomes in Hospitalized COVID-19 Patients: A Propensity Score Matched Retrospective Cohort Study. Gastroenterology. Article in press.

36. Chloroquine for Mild Symptomatic and Asymptomatic COVID-19. Clinical trials.gov identifier: NCT04333628. Available at https://clinicaltrials.gov/ct2/show/NCT04333628.

37. Chloroquine/Hydroxychloroquine Prevention of Coronavirus Disease (COVID-19) in the Healthcare Setting (COPCOV). Clinical trials.gov identifier: NCT04303507. Available at https://clinicaltrials.gov/ct2/show/NCT04303507. Accessed on 15 June 2020.

38. A randomized controlled trial of hydroxychloroquine prophylaxis for Healthcare Workers exposed to COVID-19. CTRI/2020/05/025067 (Registered on: 06/05/2020). Available at http://www.ctri.nic.in/Clin CTRI/2020/03/024402. Accessed on 31 March 2020.

39. Randomized Controlled Trial to compare efficacy of hydroxychloroquine alone and in combination with azithromycin in treatment of COVID-19. CTRI/2020/04/024904 (Registered on 28 April 2020). Available at http://www.ctri.nic.in/Clinicaltrials/pdf_generate.php?trialid=43130\&EncHid=\&mo $\mathrm{did}=\&$ compid $=\% 27, \% 2743130 \operatorname{det} \% 27$. Accessed on 15 June 2020.

40. Open labelled Randomized controlled trial to study the effect of Chloroquine in addition to standard therapy in COVID-19 patients. CTRI/2020/04/024479 (Registered on 7 April 2020). Available at http://www.ctri.nic.in/Clinicaltrials/pdf_generate.php?trialid $=42713 \&$ EncHid $=\&$ mo $\mathrm{did}=\&$ compid $=\% 27, \% 2742713 \operatorname{det} \% 27$. Accessed on 15 June 2020.

41. Hydroxy Chloroquine, in open labelled, Randomized intervention for prevention of new infection and adverse outcomes following COVID-19 infection- A Tertiary Hospital based study. CTRI/2020/03/024402 (Registered on 31 March 2020. Available at: http://ctri.nic.in/Clinicaltrials/pdf_generate.php?triali $\mathrm{d}=42638 \&$ EncHid $=\&$ modid $=\&$ compid $=\% 27, \% 2742$ 638 det $\% 27$. Accessed on 15 June 2020.

42. 'Solidarity' clinical trial for COVID-19 treatments. Available at: https://www.who.int/emergencies/ diseases/novel-coronavirus-2019/global-research-onnovel-coronavirus-2019-ncov/solidarity-clinical-trialfor-covid-19-treatments. Accessed on 15 June 2020.

43. Wong 2020 Wong YK, Yang J, He K. Caution and clarity required in the use of chloroquine for COVID- 
19. Lancet Rheumatology. 2020 April 2 (Epub ahead of print).

44. CDC 2020 Centers for Disease Control and Prevention. Interim guidelines for collecting, handling, and testing clinical specimens from persons for Coronavirus Disease 2019 (COVID-19). Available at: www.cdc.gov/coronavirus/2019nCoV/lab/guidelines-clinicalspecimens.html.

Accessed on 14 April 2020.

45. General Office of the National Health Commission of the People's Republic of China. Diagnosis and treatment protocol for COVID-19 (trial version 7). Available at: http://www.nhc.gov.cn/yzygj/ s7653p/202003/46c9294a7dfe4cef80dc7f5912eb1989 .shtml (Chinese). Accessed on 23 March 2020.

46. Mehra M, Desai S, Ruschitzka F, Patel A. Hydroxychloroquine or chloroquine with or without a macrolide for treatment of COVID-19: a multinational registry analysis. Available at: https://www.thelancet.com/journals/lancet/article/PII S0140-6736(20)31180-6/fulltextPublished/Online. Accessed on 22 May 2020.

47. WHO Halts Hydroxychloroquine Trial Over Safety Concerns? Available at https://www.npr.org/sections/ coronavirus-live-updates/2020/05/25/861913688/ who-halts-hydroxychloroquine-trial-over-safetyconcerns. Accessed on 15 June 2020.

48. WHO resumes hydroxychloroquine study for COVID-19, after reviewing safety concerns? Available at: https://www.statnews.com/2020/06/03/ who-resuming-hydroxychloroquine-study-for-covid19. Accessed on 3 June 2020.

49. 49-ICMR Issues Revised Advisory on Use of Hydroxychloroquine. Available at: https://www. bloombergquint.com/politics/icmr-issues-revisedadvisory-on-use-of-hydroxychloroquine-2. Accessed on 15 June 2020.

50. The gazette of India: extraordinary part II Sec. 3(i). G.S.R. 219(E). Notification New Delhi. Available at: https://www.mohfw.gov.in/pdf/218927g.pdf. Accessed on 26 March 2020.

Cite this article as: Shahani SR, Shahani LR. Status of chloroquine and hydroxychloroquine in COVID19 infection. Int J Basic Clin Pharmacol 2020;9:1301-9. 